\title{
A UTAH CAMPFIRE
}

Of course it is luck, whatever flame jumps at the time: the rest of the mountain steps back. It is luck that the moon is no larger, the shadows their shape that they are, and you come toward me, your shape.

But look-the world is changing, flames finding taller tongues and the moon asserting bright sparks in the trees that leap far into clouds, like fire.

And like fire the world sweeps on-

Past this place we have found, past you, the stranger in my arms.

\section{CAVE PAINTING}

It was like the moon, the open before us, when we came out of the last hills we had to cross, to be tracked by the stars. And whatever we said, we knew could be heard. Then, we learned about caves, where you have now discovered us, even these places. But for awhile we painted our hidden lives deep here, and we always tried-like this I am doing now-to find ways even deeper, with rooms that would blaze only for us and those of our kind. And even now-because a picture is a disguiseyou may never know our ultimate home with Earth over it, and the silence, where without power or worth-with nothing-we first learned to huddle together and foil the stars. 